УДК 624.131.439

\title{
СИСТЕМНЫЙ ПОДХОД К ИССЛЕДОВАНИЮ ПРОЦЕССА ОБВАЛА ГРУНТА
}

\section{Иванов Владимир Валерьевич инженер}

Службы мониторинга оборудования и гидротехнических сооружений ПАО «РусГидро»

\begin{abstract}
Аннотация: В данной статье обосновывается актуальность исследования процессов движения грунтовых масс и как следствие этого - возникновения обвалов. Приводится системный подход, основой которого является определение и анализ параметров и факторов, влияющих на процессы устойчивости и подвижности грунтов. Предложена подробная классификация состава грунта, позволяющая получить его полное описание и на основе этого оценить не только прочность грунта, но и опасность с точки зрения возможности его обсыпания и обвала.
\end{abstract}

Ключевые слова: Обвал грунта, обсыпание грунта, оценка прочность грунта, динамика грунтовых масс, системный анализ.

\section{A SYSTEMATIC APPROACH TO THE STUDY OF THE SOIL COLLAPSE PROCESS}

\section{Ivanov Vladimir Valerievich}

\begin{abstract}
This article substantiates the relevance of studying the processes of movement of soil masses and, as a consequence of this, the occurrence of landslides. It is given a systematic approach, the basis of which is the determination and analysis of parameters and factors affecting the processes of stability and mobility of soils. A detailed classification of the composition of the soil is proposed, which allows to obtain its complete description and on this basis to evaluate not only the strength of the soil, but also the danger in terms of the possibility of sprinkling and collapse.

Key words: Soil collapse, soil sprinkling, assessment of soil strength, dynamics of soil masses, system analysis
\end{abstract}




\section{Введение}

Обвал грунта и возникающие при этом проблемы для жизни и деятельности людей и даже экологические изменения происходили всегда. Примеры последних лет: обвал берега на одной из сибирских рек вызвал опасность затопления обширных территорий, имеющих хозяйственное значение; для его устранения были задействованы значительные материальнотехнические и людские ресурсы, в том числе и военная авиация.

В последнее столетие данная проблема стала особенно актуальной ввиду увеличения нагрузки на грунт в результате активного строительства высотных сооружений, крупных мостовых комплексов и т.П., и одновременных интенсивным освоением подземного пространства, в частности путем строительства линий метрополитена, подземных гаражей и других помещений, а также обширным хозяйственным освоением подземных пространств, включая добычу полезных ископаемых. Отметим, что многовековые работы в подземных шахтах также существенно изменили состояние подвижности грунтовых масс в окружении этих шахт.

Подвижки грунтовых масс, в особенности их обвал, могут привести к самым серьезным и катастрофическим последствиям. Таким образом, задача изучения подвижности грунтов, и прежде всего опасности их обвала является актуальной.

Имеется достаточно много работ по данной тематике, но они в основном имеют инженерно-практическую направленность. Работ, связанных с моделированием данных процессов относительно мало [1], [2], [3], [4], [5]. Достаточно полный перечень литературы по данной сфере приведен в [6].

Укажем, что как отмечено выше, параметры подвижности грунтов определяется широким набором факторов разного характера, начиная физических свойств самого грунта и заканчивая особенностями хозяйственной деятельности человека на данной территории. То есть рассматриваемая проблема является системной, и для ее анализа в работе используется системный поход. Работ, анализирующих данную проблему системно, с учетом всего комплекса факторов, способных оказать влияние на подвижки грунта, практически нет. Данная работа посвящена формированию совокупности факторов, способных оказать влияние на процессы устойчивости и подвижности грунтов. Содержательно работа опирается на два научных направления: динамика грунтовых масс [7] и системный анализ [8]. 


\section{Формирования состава факторов воздействия свойства подвижности грунта}

Прежде всего сформируем состав основных сущностей - всех основных «участников» процессов, связанных с подвижкой грунтов. Также опишем взаимосвязи между ними. Затем на этой основе сформируем состав факторов, которые могут оказать значимое влияние на процесс подвижки грунтов (ППГ). Наконец, на основе полученного перечня факторов необходимо будет сформировать состав показателей, описывающих все аспекты и особенности ППГ, а также описать методы оценки значений этих показателей. В дальнейшем предполагается построить ряд моделей, описывающих различные аспекты ППГ и опирающихся на сформированный состав показателей.

\section{Формирование перечня классов факторов}

Всю совокупность факторов, которые способны оказать влияние на ППГ, разобьем на следующие классы. Каждый из классов определяется одной общей для всего класса сущностью.

1. Компонентный состав грунта. То есть совокупность тех минеральнокаменных и иных природных материалов небиологического происхождения, из которых состоит грунт, с описанием их физических параметров (в частности, размеры частиц для каждого типа минерала и песочно-глиняных масс, доля в общей массе, характер разброса в грунте и др.).

2. Химические вещества неорганического и органического характера (кислоты, щелочи, соли, органические вещества), которые вследствие химических взаимодействий оказывают влияние на механические параметры грунта.

3. Вода, то есть доля воды в грунте на разной глубине и в разное время года. Также химический состав водной среды.

4. Биологическое наполнение грунта, то есть живые биологические организмы (растения, насекомые, черви, грызуны и др.) и неживые биологические ткани (перегной, гниющие остатки растений) с указанием их количественных характеристик и качественных свойств, важных для обеспечения прочности/подвижки грунта.

5. Физико-механические свойства грунта. То есть совокупность характеристик, определяющих свойства прочности грунта, условий нарушения его прочности и подвижки. Теоретически данный класс характеристик должен получаться на основе анализа свойств всех предыдущих классов. Однако, для этого потребуется очень полное описание свойств предыдущих классов, что в 
рамках данной классификации выполнить крайне затруднительно, так как, прежде всего нет научного аппарата построения соответствующих зависимостей. Но ввиду особой важности характеристик данного класса для целей работы целесообразно выделить физико-механические свойства грунта в отдельный класс.

6. Природно-климатические условия, включающие температурный режим, в котором существует грунт, в том числе морозы, наводнения, жара, ветровой и солнечный режимы.

7. Техногенная нагрузка на грунт, связанная с его хозяйственной деятельностью - техногенные отходы.

8. Мусорные отходы, то есть отходы деятельности человека, связанные с хозяйственным использованием грунта. То есть, в отличие от техногенных отходов, эти отходы не связанны с промышленной, строительной или иной другой хозяйственной деятельностью, я носят бытовой характер.

Перечисленные сущности и связанные с ними группы факторов охватывают практически все аспекты, определяющие состояние грунта на любой текущий момент времени, и как следствие, прочность грунта и возможные его подвижки.

\section{Формирование состава факторов влияния на состояние грунта}

Полученный выше набор классов факторов, определяющих все основные свойства и характеристики грунта, позволяют путем дальнейшей детализации каждого класса сформировать непосредственно перечень всех основных факторов, характеризующих конкретные грунтовые массы. В этой связи отметим, что предварительно целесообразно разбить всю анализируемую грунтовую территорию на отдельные однородные участки - однородные по всем перечисленным группам факторов. А затем провести анализ по каждому из полученных участков.

1. Компонентный состав грунта характеризуется следующими факторами и соответствующими им характеристиками; в конце описания приведена предлагаемая единица измерения:

1.1. $N_{1}$ - количество типов минерально-каменных и песочно-глинистых материалов, формирующих компонентный состав грунта. При этом предварительно необходимо иметь перечень (лучше сформированный в базу данных) по всем возможным типам компонент с полным описанием их механических и физико-химических свойств. При могут быть очень близкие по своим свойствам компоненты (например, типы глин). При описании 
компонентов, если поведение этих материалов практические никак не проявляется во времени в процессе жизненного цикла грунта, то есть с учетом возможных изменений природно-климатических условий и/или техногенных условий эксплуатации грунта, то эти разные типы материалов могут быть объединены в один тип.

1.2.Долевые части каждого материала в грунте $D_{1, i}\left(i=\overline{1 ; N_{1}}\right)$ - длина $i$-го компонента, в процентах); причем долевые части в массовом исчислении $D_{1, i}^{(m)}$ и в объемном исчислении $D_{1, i}^{(V)}$.

1.3.Пространственное распределение каждого типа материалов $R_{1, i}\left(i=\overline{1 ; N_{1}}\right.$ ), в том числе по высоте $R_{1, i}^{(h)}$ и в горизонтальной плоскости $R_{1, i}^{(p)}(h)$ (измеряется доля на см высоты)на разных глубинах $h$ (измеряется в доле на $\left.\mathrm{CM}^{2}\right)$.

1.4.Размерное распределение для каждого типа материала $S_{1, i}(d)\left(i=\overline{1 ; N_{1}}\right.$ ). То есть для материала $i$-го типа доля частиц диаметра $d$ при всевозможных допустимых значениях $d$. Данный фактор может зависеть также от глубины $h$ внутри грунта по вертикальному измерению.

1.5.Пустоты в грунте, объемная величина всех пустот в единице объема $V^{\text {(пуст) }}$, а также дисперсия колебаний объемов отдельных одиночных пустых шариков $\sigma^{\text {(нас) }}$.

2. Химические вещества неорганического и органического характера. Характеризуется следующими факторами:

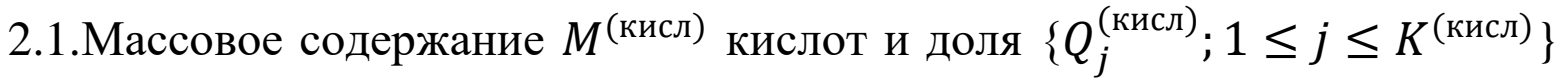
кислоты каждого типа (описание кислоты приводится), где $K^{\text {(кисл) }}$ количество основных типов кислот в почве. Если $K^{(\kappa и с л)}=0$, то типовых кислот в почве нет.

2.2. Массовое содержание $M^{\text {(соль) }}$ солей и доля $\left\{Q_{j}^{\text {(соль) }} ; 1 \leq j \leq K^{\text {(соль) }}\right\}$ соли каждого типа (описание соли приводится), где $K^{\text {(соль) }}$ - количество основных типов солей в почве. Если $K^{\text {(кисл) }}=0$, то типовых солей в почве нет.

2.3.Массовое содержание $M^{(\text {щел) } щ е л о ч е и ̆ ~ и ~ д о л я ~}\left\{Q_{j}^{(\text {соль })} ; 1 \leq j \leq K^{\text {(щел) }}\right\}$ щелочи каждого типа (описание щелочи приводится), где $K^{(щ е л) ~}-$ количество основных типов щелочей в почве. Если $K^{\text {(щел) }}=0$, то типовых щелочей в почве нет. 
2.4.Массовое содержание $M^{(\text {орг })}$ органических веществ и доля $\left\{Q_{j}^{(\text {орг })} ; 1 \leq\right.$ $\left.j \leq K^{\text {(орг) }}\right\}$ органического вещества каждого типа (описание каждого органического вещества приводится), где $K^{(\text {орг) }}$ - количество основных типов органических веществ в почве. Если $K^{(\text {орг })}=0$, то типовых органических веществ в почве нет.

3. Вода. Является очень важным фактором, определяющим состояние грунта. Характеризуется массовой долей $M^{\text {(вода) }}(h, T)$ на глубине $h$ в $T$-ый день года. Глубина $h$ обычно ограничивается некоторой предельной величиной $h_{\max }$.

4. Биологическое наполнение грунта. Все биологические организмы в почве разобьём на следующие группы.

4.1.Растения, включая лишайники и грибки; их массовую долю на глубине $h$ обозначим через $M^{(\text {раст) }}(h)$. При необходимости может быть произведена дифференциация по видам растений.

4.2.Перегной, то есть сгнившие остатки растений; ; их массовую долю на глубине $h$ обозначим через $M^{\text {(пергн) }}(h)$.

4.3.Насекомые; пусть $M_{j}^{\text {(нас) }}(h)$ есть плотность насекомых $j$-го вида, то их

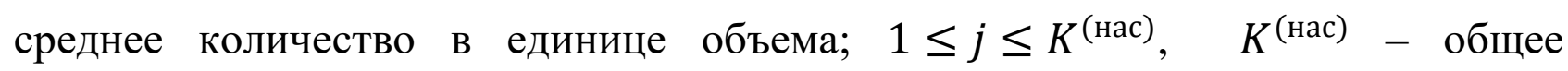
количество типов насекомых.

4.4.Мелкие животные, прежде всего, грызуны; пусть $M_{j}^{(ж и в)}(h)$ есть плотность животныхј-го вида, то их среднее количество в единице объема; $1 \leq$ $j \leq K^{(\text {нас) }}, K^{\text {(нас) }}$ - общее количество типов животных.

5. Физико-механические свойства грунта. Это прежде всего:

5.1.Прочностные характеристики грунта: величина давления $F\left(T, M^{(\text {вод) }}(h)\right)$, вызывающая разрыв грунта при температуре грунта $T$,

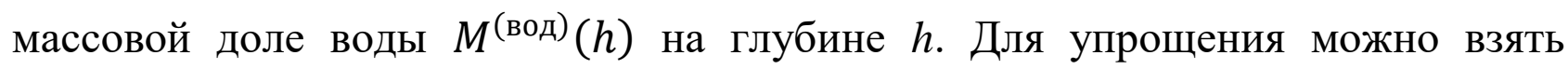
среднее значение доли воды по глубине, то есть зависимость от $h$ отбросить.

5.2.Средняя плотность грунта $\rho\left(h . M^{(\text {вод) }}(h)\right)$ на глубине $h$ при массовой доле воды $M^{(\text {вод) }}(h)$.

5.3.Степень эластичности грунта, что связано, в частности, наличие в грунте живых растений и наличием пустот; $k^{(\text {сж) }}$ коэффициент сжимаемости грунта. 
5.4.Устойчивость грунта к вибрационным воздействиям, то есть

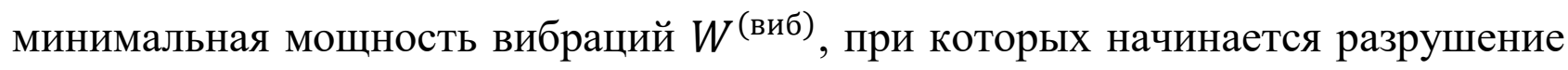
грунта.

6. Природно-климатические условия. Основные характеристики:

6.1.Изменения температуры $T$ по времени $t$, то есть зависимость $T(t)$,

6.2.Изменение величины осадков $S$ по времени $t$, то есть зависимость $S(t)$; прежде всего, дождевых осадков, остальные виды осадков (снег, град) проявляются после их таяния.

6.3.Ветер и воздушные бури разных типов; ветер может выдувать грунт, если он недостаточно плотен, а воздушные бури его отрывать и уносить, а также досыпать сверху. Обозначим через $R(t)$ силу ветра в момент времени $t$.

7. Техногенная нагрузка на грунт. Можно описывать с помощью следующих величин:

7.1.Величины давления на грунт $P(t)$ в момент времени $t$, производимого в результате ведения хозяйственной деятельности.

7.2. Мощность вибрационного воздействия на грунт $U(t)$ в момент времени $t$, производимого в результате ведения хозяйственной деятельности.

7.3.Мощность взрывного воздействия на грунт $E(t)$ в момент времени $t$, производимого в результате ведения хозяйственной деятельности.

7.4.Глубина $H(t)$ копания грунта и объем $V^{(г р)}(t)$ выкопанной грунтовой массы в момент времени $t$.

8. Мусорные отходы. Выделим следующие показатели.

8.1.Массовая доля $O^{\text {(нер) }}$ неразлагаемых или почти неразлагаемых отходов. Данная величина может уточняться по типам неразлагаемых отходов, то есть $\left\{O_{j}^{(\text {нер) }}\right\}$ есть массовая доля неразлагаемых отходов $j$-го вида, то их среднее количество в единице объема; $1 \leq j \leq K^{\text {(нер) }}, \quad K^{\text {(нер) }}-$ общее количество видов неразлагаемых отходов.

8.2.Массовая доля $O^{(\text {нер) }}(t)$ слабо разлагаемых отходов в момент времени $t$. Данная величина может уточняться по типам разлагаемых отходов, то есть $\left\{O_{j}^{(\text {нер) }}(t)\right\}$ есть массовая доля слабо разлагаемых отходов $j$-го вида в момент времени $t$, то их среднее количество в единице объема; $1 \leq j \leq K^{\text {(разл) }}, K^{\text {(разл) }}$ - общее количество видов слабо разлагаемых отходов.

Таким образом, получена классификационная таблица, включающая 8 сущностей, 27 факторов и 36 видов характеристик. Приведенная классификация состава грунта до уровня отдельных характеристик позволяет получить полное 
описание грунта и на этой основы оценить прочность грунта и его опасность с точки зрения возможности обсыпания и обвала. Для решения указанной задачи необходимо прежде всего довести приведенную классификацию до уровня отдельных показателей с описанием методов оценки их значений, затем вывести соотношения для всех перечисленных выше функций и построить формулы для комплексной оценки прочности грунта по построенной совокупности показателей.

\section{Заключение}

В работе поставлена задача системной оценки прочности грунта с учетом комплексной оценки влияния всех факторов самой разной природы, которые способны оказать влияние на прочность грунта. Проведена классификация совокупности этих факторов на основе системного подхода. Получена трехуровневая классификационная структура, содержащая 8 элементов первого уровня, 27 элементов второго уровня и 36 элементов третьего уровня. Приведенная классификационная структура после формирования вида всех введенных функциональных зависимостей может быть использована для оценки прочности грунта.

\section{Список литературы}

1. Иванов В.В. Математическое моделирование нестационарной фильтрации упругой жидкости в неоднородном пласте/Иванов В.В., Баламирзоев А.Г.// Вестник Дагестанского государственного технического университета. Технические науки.-2013.- №4(31).- С.50-54.

2. Орнатский Н.В. Механика грунтов.М.МГУ.1962.448с.

3. Бережной Д.В., Кузнцова И.С., Саченков А.А. Моделирование пластичного деформирования грунта в зоне опоры многопролетного моста.// Ученые записки Каз. Гос. Ун-та, 2010, т. 152, кн.1, с. 54-61

4. Моделирование замораживания грунтов https://frost3d.ru/modelirovaniezamorajivaniya-gruntov/

5. http://baraholka.com.ru/bulls/prodam-knigi-mekh.gruntov.-osnovaniya-ifundamenty-v-novosibirske-2049557.htm

6. Ширяева М.П. Моделирование процессов пластического деформирования грунтов оснований. Автореферат на соиск. степени канд. Техн. Наук. - Новочеркасск, 2007. 
7. Сергеев Е.М., Голодковская Г.А. и др. Грунтоведение. М.МГУ.1973г.388c.

8. Силич М.П., Силич В.А., Основы теории систем и системного анализа: учеб. пособие. - Томск: Изд-во Томск. гос. ун-та систем управления и радиоэлектроники, 2013. - 340 с.

(C) В.В. Иванов 2020 